\title{
Cardiovascular Risk in Chronic Obstructive Pulmonary Disease
}

\author{
Toshiharu Ninomiya, MD, PhD
}

C hronic obstructive pulmonary disease (COPD) is a growing global epidemic and the associated mortality rate is rising. COPD is projected to jump from the 6th leading cause death in 1990 to the 3rd worldwide by the year 2020. ${ }^{1}$ The Nippon COPD Epidemiology study reported that the prevalence of people with a reduced expiratory flow was $10.9 \%$ in Japanese people aged 40 years or older. ${ }^{2}$ A metaanalysis also revealed that the global prevalence of COPD in adults aged 40 years or older is $9-10 \%$. $^{3}$

\section{Article p 2309}

COPD is a disorder characterized by reduced maximum expiratory flow and slow forced emptying of the lungs because of varying combinations of the airway disease and emphysema. Therefore, pulmonary parameters such as forced expiratory volume in $1 \mathrm{~s}\left(\mathrm{FEV}_{1}\right)$ or partial pressure of arterial oxygen have been considered to estimate severity and prognosis of disease and current therapy targets exclusively the lung's function or its exacerbation. ${ }^{4}$ However, it is increasingly recognized that COPD is associated with significant extrapulmonary disorders, the so-called "systemic effects of COPD", and that patients with COPD have further impaired functional capacity and health-related quality of life. ${ }^{5}$ Because the extrapulmonary disorders increase the risks of hospitalization, mortality and healthcare cost for patients with COPD, these "systemic effects" are

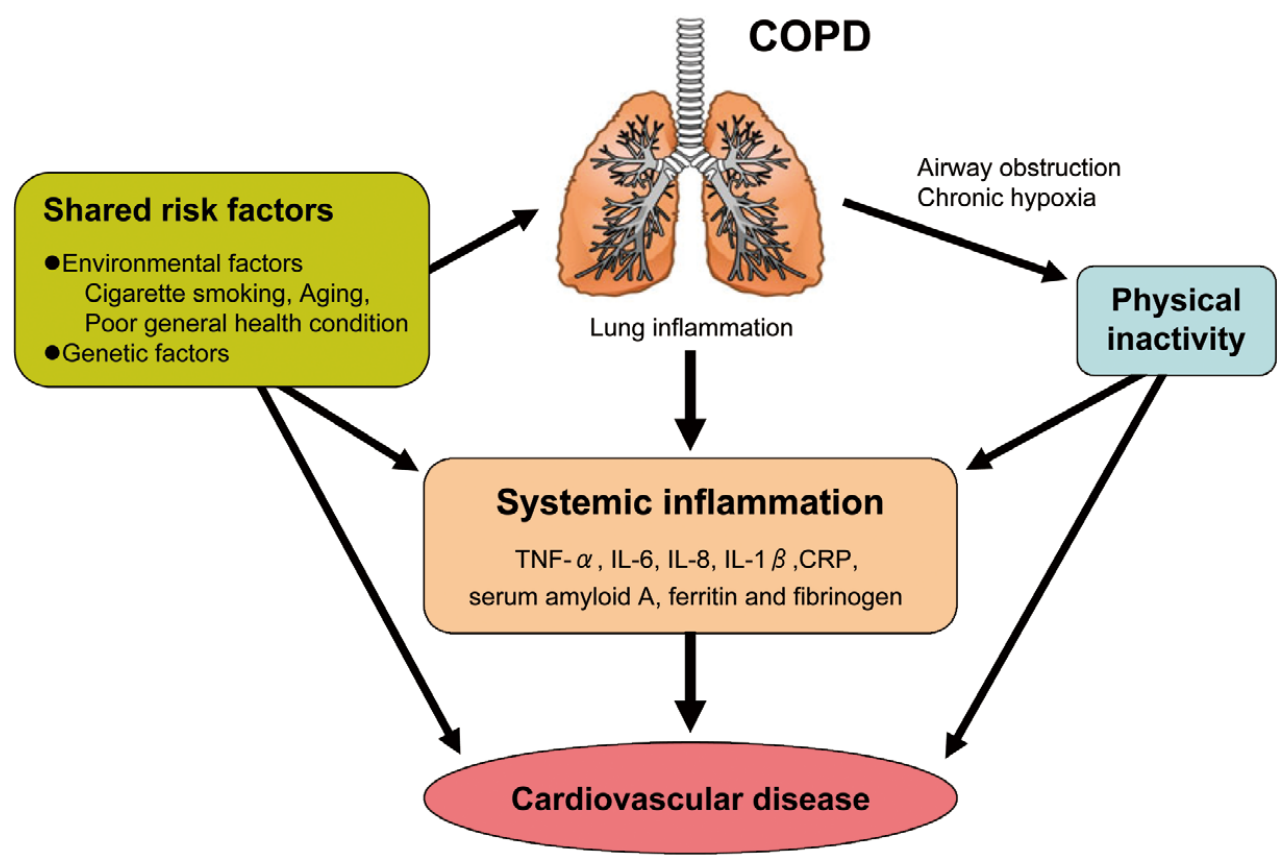

Figure. Possble mechanisms underlying the association between chronic obstructive pulmonary disease (COPD) and cardiovascular disease.

The opinions expressed in this article are not necessarily those of the editors or of the Japanese Circulation Society.

Received July 22, 2014; accepted July 22, 2014; released online August 4, 2014

Center for Cohort Studies, Graduate School of Medical Sciences, Kyushu University, Fukuoka, Japan

Mailing address: Toshiharu Ninomiya, MD, PhD, Center for Cohort Studies, Graduate School of Medical Sciences, Kyushu University,

3-1-1 Maidashi, Higashi-ku, Fukuoka 812-8582, Japan. E-mail: nino@intmed2.med.kyushu-u.ac.jp

ISSN-1346-9843 doi:10.1253/circj.CJ-14-0809

All rights are reserved to the Japanese Circulation Society. For permissions, please e-mail: cj@j-circ.or.jp 
a topic of increasing concern.

The pulmonary and cardiovascular systems are intimately related. ${ }^{6}$ Cardiovascular disease (CVD) is a major cause of mortality and morbidity in patients with COPD. ${ }^{7}$ Severe COPD causes pulmonary hypertension and right heart failure as a response to increased vascular resistance in the lung. ${ }^{6-8}$ Conversely, recurrent episodes of elevated pulmonary capillary pressure caused by heart failure lead to lung fibrosis and impaired lung function. ${ }^{8}$ Although these are direct hemodynamic cardiopulmonary interactions,${ }^{6}$ cardiovascular involvement in patients with COPD is much more complex. Several epidemiological studies have also provided strong evidence that people with reduced lung function have an increased risk of CVD. ${ }^{5,9-11}$ Reduced FEV 1 is associated with 2- to 3-fold greater risk of coronary artery disease (CAD), stroke, and sudden cardiac death, independent of cardiovascular risk factors. ${ }^{11}$ It has been also shown that COPD patients have increased arterial stiffness defined as increased aortic pulse wave velocity. ${ }^{12}$ Therefore, COPD appears to be an important risk factor for CVD.

In this issue of the Journal, Min et al ${ }^{13}$ show that reduced lung function is significantly associated with cardiovascular mortality in their prospective cohort study of a representative sample of the US adult population - the Third Nutrition and Health Examination Survey (NHANES III). Individuals with the lowest $\mathrm{FEV}_{1}$ or forced vital capacity had higher risk of death from CVD and CAD. These associations remained significant after adjusting for cardiovascular risk factors including age, sex, cigarette smoking, body mass index, total cholesterol, history of hypertension, dyslipidemia, diabetes, asthma or COPD, and systemic inflammatory markers. Intriguingly, the subgroup analysis of C-reactive protein (CRP) levels found that individuals with reduced lung function had a significantly greater risk of cardiovascular mortality, regardless of CRP level, although the cardiovascular risks were highest in those with both reduced lung function and higher CRP level.

The underlying mechanisms of the association between COPD and CVD are not fully understood, but several possible explanations are considered (Figure). Initially, both COPD and CVD share similar risk factors, namely, cigarette smoking, aging, and poor general health condition, which were also observed in the baseline characteristics of this study population. ${ }^{4,14}$ Furthermore, increased mortality from CVD could reflect systemic endothelial cell dysfunction as a result of systemic inflammation. Persistent low-grade systemic inflammation predisposes to vulnerable plaque formation in arteries. COPD is characterized by not only abnormal inflammatory response of the lung parenchyma, but also persistent systemic inflammation, including systemic oxidative stress, activation of circulating inflammatory cells and higher levels of proinflammatory cytokines. ${ }^{4,9,15}$ Epidemiological evidence supports that patients with COPD have increased circulating levels of several inflammatory cytokines, including tumor necrosis factor- $\alpha$, interleukin (IL)- 6 , IL- 8 and IL- $1 \beta$ and acute-phase proteins including CRP, serum amyloid A, ferritin and fibrinogen. ${ }^{15}$ These cytokines are also increased in the sputum and bronchoalveolar lavage fluid of patients with COPD, suggesting that systemic inflammatory cytokines represent an over- spill of inflammatory mediators from the lung parenchyma. ${ }^{7}$ In this study, however, the significant link between COPD and CVD mortality was observed after adjusting for these risk factors as well as for CRP and ferritin levels, suggesting that other factors are possibly also involved. Other possible mechanisms include common genetic predisposition, and physical inactivity as a consequence of progressive airflow limitation and chronic hypoxia. These issues should be investigated further.

In summary, COPD seems to be a risk factor for death from CVD. The mechanism underlying the link between COPD and cardiovascular risk remain unclear, but spillover of inflammatory mediators from the lung and consequent systemic inflammation partially contribute to the development of CVD. A better understating of the cardiovascular effects of COPD may lead to appropriate management strategies, resulting in better prognosis for patents with COPD.

\section{Conflict of Interest/Disclosures}

None.

\section{References}

1. Murray CJ, Lopez AD. Alternative projections of mortality and disability by cause 1990-2020: Global Burden of Disease study. Lancet 1997; 349: $1498-1504$.

2. Fukuchi Y, Nishimura M, Ichinose M, Adachi M, Nagai A, Kuriyama T, et al. COPD in Japan: The Nippon COPD Epidemiology study. Respirology 2004; 9: 458-465.

3. Halbert RJ, Natoli JL, Gano A, Badamgarav E, Buist AS, Mannino DM. Global burden of COPD: Systematic review and meta-analysis. Eur Respir J 2006; 28: 523-532.

4. Pauwels RA, Buist AS, Calverley PM, Jenkins CR, Hurd SS. Global strategy for the diagnosis, management, and prevention of chronic obstructive pulmonary disease: NHLBI/WHO global initiative for chronic obstructive lung disease (GOLD) workshop summary. Am J Respir Crit Care Med 2001; 163: 1256-1276.

5. Agusti AG, Noguera A, Sauleda J, Sala E, Pons J, Busquets X. Systemic effects of chronic obstructive pulmonary disease. Eur Respir J 2003; 21: 347-360.

6. Bronicki RA, Anas NG. Cardiopulmonary interaction. Pediatr Crit Care Med 2009; 10: 313-322.

7. Barnes PJ, Celli BR. Systemic manifestations and comorbidities of COPD. Eur Respir J 2009; 33: 1165-1185.

8. Kee K, Naughton MT. Heart failure and the lung. Circ J 2010; 74: $2507-2516$.

9. Sin DD, Man SF. Why are patients with chronic obstructive pulmonary disease at increased risk of cardiovascular diseases?: The potential role of systemic inflammation in chronic obstructive pulmonary disease. Circulation 2003; 107: 1514-1519.

10. Sin DD, Anthonisen NR, Soriano JB, Agusti AG. Mortality in COPD: Role of comorbidities. Eur Respir J 2006; 28: 1245-1257.

11. Sin DD, Wu L, Man SF. The relationship between reduced lung function and cardiovascular mortality: A population-based study and a systematic review of the literature. Chest 2005; 127: 1952-1959.

12. Sabit R, Bolton CE, Edwards PH, Pettit RJ, Evans WD, McEniery $\mathrm{CM}$, et al. Arterial stiffness and osteoporosis in chronic obstructive pulmonary disease. Am J Respir Crit Care Med 2007; 175: 12591265 .

13. Min KB, Min JY. Reduced lung function, C-reactive protein, and increased risk of cardiovascular mortality. Circ J 2014; 78: 23092316.

14. JCS Joint Working Group. Guidelines for Smoking Cessation (JCS 2010): Digest version. Circ J 2012; 76: 1024-1043.

15. Gan WQ, Man SF, Senthilselvan A, Sin DD. Association between chronic obstructive pulmonary disease and systemic inflammation: A systematic review and a meta-analysis. Thorax 2004; 59: 574580 . 